\title{
A Concept of Robotic System with Force-Controlled Manipulators for On-Orbit Servicing Spacecraft
}

\author{
I. Dalyaev, V. Titov and I. Shardyko
}

\begin{abstract}
To enhance longevity and safety of unmanned spacecraft, especially on high orbits including geostationary ones, it is thought suitable to exploit on-orbit servicing (OOS) spacecraft (servicers) equipped with manipulation system. The employment of the manipulator is by the requirement for fine manipulation in tasks such as refueling, equipment replacement, orbit correction and maintenance tasks. The key feature of a manipulator to fulfill this list is the force-torque feedback. This paper describes a general concept of the manipulator to carry out the on-orbit servicing tasks along with the common and kinematic description of a ground prototype. A brief look at graphical user interface designed for testing purposes is represented. A ground validation facility is described and the description of series of performed tests is included along with conclusions.
\end{abstract}

Keywords On-orbit servicing - Space robotic systems • Supervised autonomy Ground testing • Validation - Control system · Force-torque control Robot software

\section{Introduction}

Taking into account the expanding exploration and exploitation of space, it is important to have facilities capable of conducting maintenance of the spacecraft being currently used and coping with such situations as failures or fuel depletion in that spacecraft, further addressed as client. Namely, this facility should be able to capture the client or dock with it, to replace the failed unit, to refuel the object,

I. Dalyaev $\cdot$ V. Titov $\cdot$ I. Shardyko $(\bowtie)$

RTC, Saint-Petersburg, Russia

e-mail: i.shardyko@rtc.ru

I. Dalyaev

e-mail: igor@rtc.ru

V. Titov

e-mail: vtitov@ rtc.ru 
to perform required maintenance tasks and to drive the client away from its orbit if it cannot continue functioning [1]. This goal can be achieved by a space system consisting of host spacecraft and robotic system designed to execute specified tasks.

\section{A Servicing Spacecraft Concept}

A number of projects and prototypes is known in the research area, which have been developed throughout the world in recent years. Those that stand out include “Orbital Express" experiment carried out by NASA in 2007 [2], project DEOS by DLR, Germany [3], and a prolonged experiment previously related as FREND with its follower being now developed by DARPA known as Phoenix [4]. The latter is shown on Fig. 1 (left).

This paper presents a concept of spacecraft that was designed for the tasks given above, which is depicted on Fig. 1 (right). It comprises a host spacecraft, a manipulator, a tool kit, a payload unit and a vision system unit. An approach with only one manipulator was chosen after the appropriate research due to its less weight and cost whereas providing essential functionality $[5,6]$.

\section{Functional and Technical Description of the Manipulation System}

Considering the servicer's required functionality, a list of tasks for manipulation system can be drawn, including [7]:
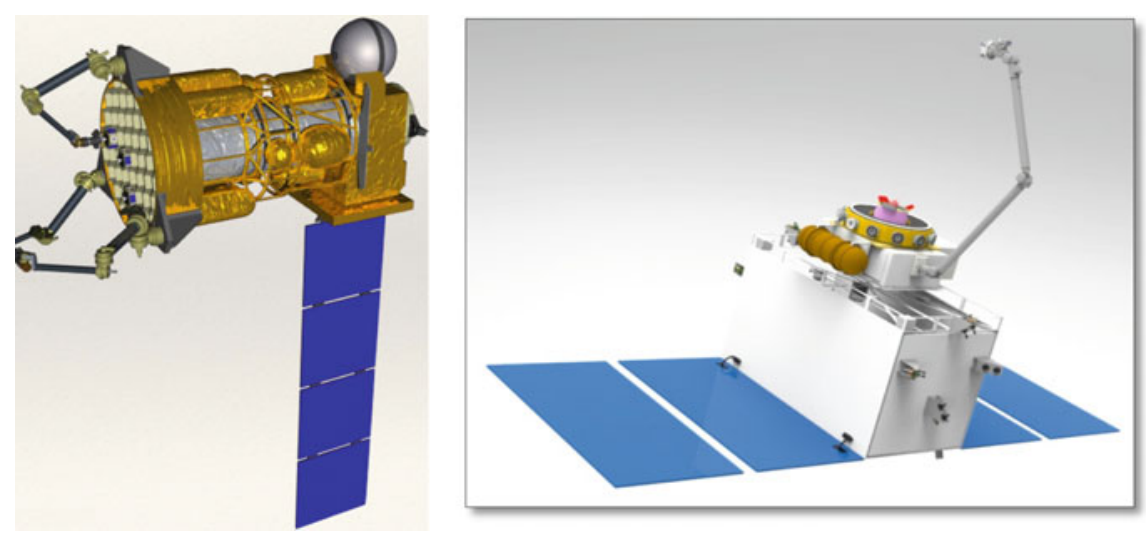

Fig. 1 DARPA phoenix project and spacecraft for on-orbit servicing (Geometric model) 
- grasping (and releasing) objects;

- transporting objects;

- inserting objects into their receptacles;

- executing tool-oriented manipulations: cutting, drilling, screwing, etc. (operations).

Consequently, the manipulator meets a number of requirements resulting from the list. First of all, it has an end-effector that enables the diversity of supported operations by connecting with different tools, including a gripper and a tool for each operation. Next, the manipulator has an appropriate 7-DOF arm kinematic structure to allow the full working area coverage and the ability to exchange tools, wherein the excessiveness kinematics provide the essential dexterity. Each DOF is represented by a revolute joint. Besides, the arm produces sufficient pull and push force on the end-effector either with or without the tooltip.

There are some external factors that affect the manipulator design. When using the servicer on high orbits such as geostationary ones, or in lunar or Martian space, there will be significant signal delays leading to instability in manipulator behaviour if an operator controls it from Earth. Also, the high cost of both the assumed mission and the client requires an ultimate level of safety while performing servicing tasks. As a result, the control system of manipulator has supervised autonomy mode, when an operator needs only to appoint a task and the local control system should perform and verify all required actions. Nevertheless, an operator still has the ability to take over control and stop any action at the arbitrary moment of time in case of anomalies or undesired behaviour. The force control subsystem is implemented as well to make the local control system capable of tracking contact tasks, adapting motion trajectories accordingly and stopping motion if contact forces or any joint torques exceed allowed values.

Each of the manipulator joints is a mechatronic unit, which consist of a brushless DC-motor, a compound gear of planetary and harmonic drive parts, motor position sensor, joint position sensor and joint torque sensor. A motor position sensor also acts as a joint speed sensor. High reduction ratio provides for high forces and torques required to perform contact tasks while the speed is not of great importance in context of servicing operations. Finally, each joint contains a group of housekeeping sensors, ensuring temperature monitoring and overcurrent protection.

\section{Manipulator Control System}

Manipulator control system provides a number of motion types to conform with the manipulator task list:

- rigid moving along the required trajectory in Cartesian space;

- moving with required velocity vector in Cartesian space;

- applying required force-torque vector (FT-control) in Cartesian space; 
- hybrid motion combining moving along some surface with applying force against it;

- moving along the required trajectory in Cartesian space with impedance control.

Mentioned Cartesian space may be represented by a Cartesian coordinate system, either attached to the manipulator base or to its end-effector, or taught to manipulator by an operator. To set the orientation the system of Euler angles ZYX has been chosen [8, p. 11].

To gain assurance that the control system will successfully work on real prototype, an experimental model of manipulator has been manufactured and a test software has been written. A picture of experimental model along with its kinematics is shown in Fig. 2, screenshots of a software interface window are depicted in Fig. 3. The left and right parts of Fig. 3 show two different kind of input capabilities. In the interface on the left an operator can only enter data for performing a one-coordinate motion while on the right it is possible for an operator to set motion requirements on any number of coordinates up to six.
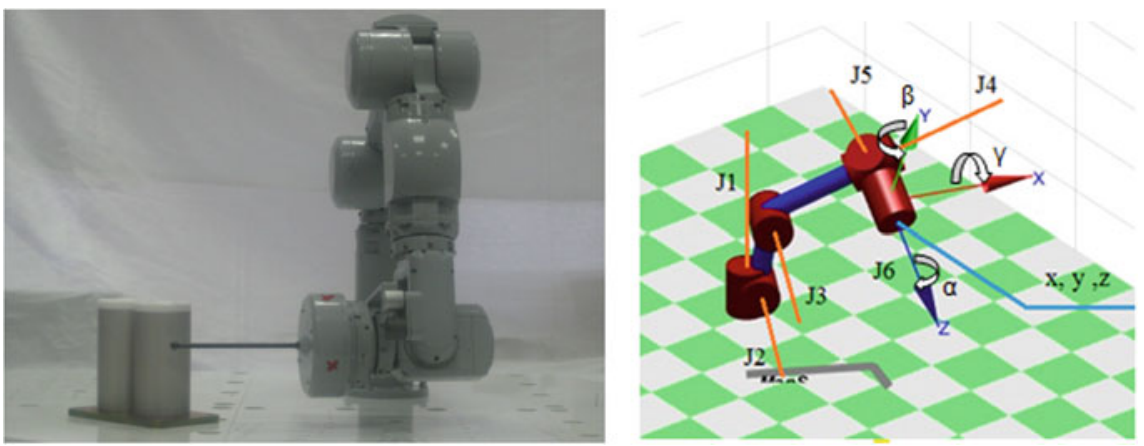

Fig. 2 Experimental model of manipulator and its kinematics
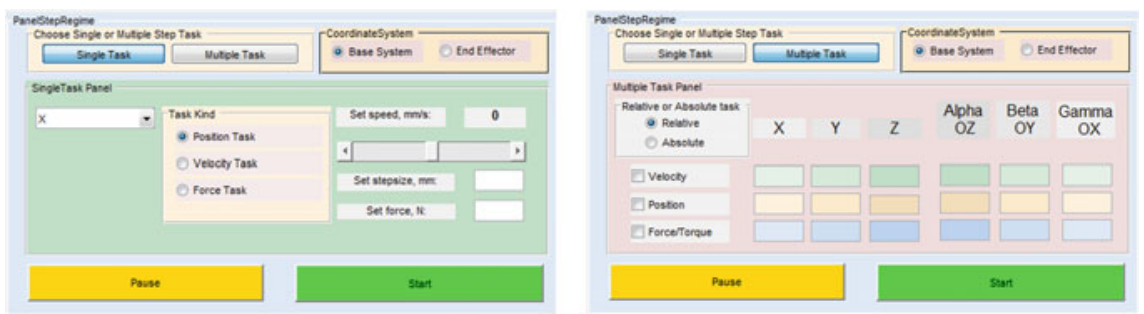

Fig. 3 Test software interface 
The last three motion types belong to force control methods, which are crucial for autonomous system in undetermined environment ensuring its safety. A research has been conducted to formulate corresponding control laws and test them on kinematic and dynamic models of the manipulator to verify the laws so that they can be implemented in the software.

\section{Experimental Model Testing on the Ground Validation Facility}

A series of experiments has been conducted to test the mentioned control laws. Experiments were held on the ground validation facility (testground) also designed and manufactured in this project. The testground, depicted in Fig. 4, consists of several areas, which are [9]: "Smooth Trajectory" (2), "Rough Trajectory" (3), "Sockets" (4), "Dynamometer" (5), "Screw Connections" (6), "Scales" (7). The given numeration is in accord with Fig. 4, number 1 stands for testground base.

"Trajectory" areas have been designed to examine the ability of control system to cope with obstacles unknown beforehand. The task was to perform a spline trajectory connecting the points located so that there was a part of a solid object on the straight line between them. Moving in accordance with the impedance control law, the manipulator arm was able to make the motion due to a virtual stiffness that allowed necessary deviations from desired trajectory while virtual torques and forces remained moderate. When it was impossible to execute the command

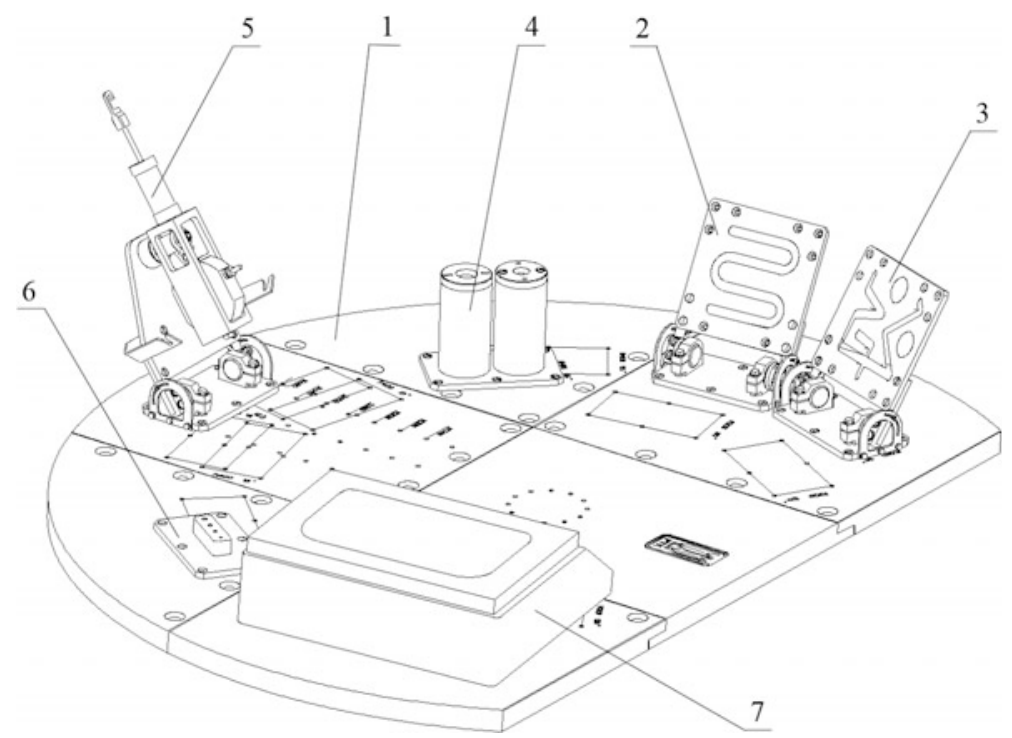

Fig. 4 Ground validation facility 
without exceeding the limit FT-values, the arm was stopped to wait for further commands.

The idea of "Sockets" area was to simulate the process of linking two mutual parts (peg-in-hole operation). A case of particular interest here was when the relative position of the parts was not determined strictly, i.e. there was a linear or angular displacement between axes of these parts. Again the impedance control was in action and the range of permitted displacements was found for which the task had been successfully executed. The defined range was admitted as sufficient to meet the manipulator requirements. In the cases when a displacement was out of range, the FT-feedback values exceeded the limits and the system stopped itself to wait for the response of an operator.

As "Dynamometer" area speaks for itself, its objective was to apply force in the chosen direction. The same goes to "Screw Connections" area, where the main criterion was the equality between the task and actual tightening torque. In the course of these experiments the FT-control was applied to the manipulator motion. Tests showed the conformity of actual values to the appropriate tasks.

The purpose of "Scales" area was to examine the behavior of the arm when moving along the scales surface, applying to this surface a force of the required degree. The description clearly states that the task conforms to a hybrid velocity-force motion type specification. The experiments included a series of moves along the scales surface with different velocity and force tasks. Actual velocity was evaluated by the vector of joint speeds and actual force was measured by the scales. The deviations from the required values were within $10 \%$ for force and $5 \%$ for linear velocity.

\section{Conclusions}

This paper presents the concept of a servicing spacecraft with a force-controlled manipulation system along with an experimental model and a facility designed to tune and test the control system. The list of tasks was described for both spacecraft and manipulator and a set of control laws was formed. A number of experiments were held with the model on the testground, successful results of which verified the applied control laws. Future work will include more thorough design of a servicer mechanical system and selection of electronic components suitable for the target environment. Conversely, special attention will be paid to the enhancing of manipulator performance related to increasing motion smoothness and expanding the number of feasible tasks.

Acknowledgements Research are carried out (conducted) with the financial support of the state represented by the Ministry of Education and Science of the Russian Federation. Agreement (contract) no. 14.578.21.0046 16.Sept 2014 Unique project Identifier: RFMEFI57814X0046 


\section{References}

1. Разработка технического (проектного) облика робототехнической системы с очувствленными по усилению манипуляторами в составе сервисного космического аппарата: отчёт о ПНИ (2 этап - промеж.) / ЦНИИ РТК. - 2015. - 137 с

2. On-Orbit Mission Updates [Электронный pecypc]. URL http://archive.darpa.mil/ orbitalexpress/mission_updates.html (дата обращения: 10.09.2016)

3. Reintsema, D., Thaeter, J., Rathke, A., Naumann, W., Rank, P., Sommer, J.: DEOS-The German robotics approach to secure and de-orbit malfunctioned satellites from low earth orbits. In: Robotics and Automation in Space (i-SAIRAS), Sapporo, Japan (2010)

4. Henshaw, C.G.: The DARPA phoenix spacecraft servicing program: Overview and plans for risk reduction. Naval Center for Space Technology. In: The 12th International Symposium on Artificial Intelligence, Robotics and Automation in Space, Montreal, Canada (2014)

5. Технический облик средств робототехнического обеспечения сервисного спутника, предназначенного для продления сроков активного существования космических аппаратов/Даляев. И.Ю, Шардыко И.В., Кузнецова Е.М. // Экстремальная робототехника: Труды международной научно-технической конференции. - СПб: Издво « Политехника-сервис », 2015. - С. 1181 - 186

6. Lopota, A., Dalyaev, I., Shardyko, I., Kuznetcova, E., Belezyakov, I.: Means of robotic support for on-orbit servicing. In: B. Katalinic (ed.) Proceedings of the 26th DAAAM International Symposium, pp. 0865-0870, Published by DAAAM International, ISBN 978-3-902734-07-5, ISSN 1726-9679, Vienna, Austria

7. Разработка технического (проектного) облика робототехнической системы с очувствленными по усилению манипуляторами в составе сервисного космического аппарата: отчёт о ПНИ (1 этап - промеж.) / ЦНИИ РТК. - 2014. -- 202 с

8. Siciliano, B., Khatib, O.: Handbook of Robotics, 1611 p. Springer, Berlin (2008)

9. Разработка технического (проектного) облика робототехнической системы с очувствленными по усилению манипуляторами в составе сервисного космического аппарата: отчёт о ПНИ (4 этап - промеж.) / ЦНИИ РТК. - 2016. - 127 с

Open Access This chapter is licensed under the terms of the Creative Commons Attribution 4.0 International License (http://creativecommons.org/licenses/by/4.0/), which permits use, sharing, adaptation, distribution and reproduction in any medium or format, as long as you give appropriate credit to the original author(s) and the source, provide a link to the Creative Commons license and indicate if changes were made.

The images or other third party material in this chapter are included in the chapter's Creative Commons license, unless indicated otherwise in a credit line to the material. If material is not included in the chapter's Creative Commons license and your intended use is not permitted by statutory regulation or exceeds the permitted use, you will need to obtain permission directly from the copyright holder.

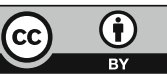

